\title{
Texto livre, trabalho colaborativo e imprensa esco- lar na Pedagogia Freinet
}

\author{
Norberto Dallabrida \\ Denise Furtado \\ Universidade do Estado de Santa Catarina (Brasil)
}

\section{Resumo}

Há atualidade na abordagem da Pedagogia Freinet e em suas formas de ensinar? Buscando refletir sobre essa questão, o presente artigo trata de discorrer sobre três práticas, consideradas fundamentais para que seja possivel entender a Pedagogia Freinet e sua essência, quais sejam: o texto livre, o trabalho colaborativo e o jornal escolar. Trata-se de uma pesquisa qualitativa, realizada a partir do método bibliográfico, baseada em livros, artigos e revistas já publicados sobre o tema abordado. Freinet traz consigo um ideal de educação que reflete seu ideal de sociedade, seus princípios e valores enquanto pensador e enquanto docente. Dessa forma, apresentaremos argumentos e autores que busquem comprovar as implicações positivas das práticas de Freinet para o ensino e a atualidade desses métodos para a construção de uma prática docente significativa e democrática.

Palavras-chave: Pedagogia Freinet. Prática docente. Métodos alternativos. Inovação pedagógica.

\section{Free text, collaborative work and school press in Freinet's Pedagogy}

\begin{abstract}
Is there actuality in Freinet's Pedagogy approach and its ways of teaching? Seeking to reflect on these question, this article deals with three practices, considered fundamental to understand Freinet's Pedagogy and its essence, namely: free text, collaborative work and the school newspaper. This is a qualitative research, conducted from the bibliographic method, based on books, articles and journals already published on the topic discussed. Freinet brings with him an ideal of education that reflects its ideal of society, his principles and values as a thinker and as a teacher. Thus, we will present arguments and authors who seek to prove the positive implications of Freinet's practices for teaching, and the actuality of these methods for the construction of a significant and democratic teaching practice.

Keywords: Freinet's Pedagogy. Teaching practice. Alternative methods. Pedagogical innovation.
\end{abstract}




\section{Texto libre, trabajo colaborativo y prensa escolar en la Pedagogía Freinet}

\section{Resumen}

¿Existe actualidad en el enfoque de la Pedagogía de Freinet y sus formas de enseñar? Tratando de reflexionar sobre esta cuestión, este artículo discute tres prácticas, consideradas fundamentales para que sea posible comprender la Pedagogía de Freinet y su esencia, a saber: el texto libre, el trabajo colaborativo y el periódico escolar. Esta es una investigación cualitativa, realizada desde el método bibliográfico, basada en libros, artículos y revistas ya publicados sobre el tema abordado. Freinet aporta un ideal de educación que refleja su ideal de sociedad, sus principios y valores como pensador y como maestro. Por lo tanto, presentaremos argumentos y autores que buscan probar las implicaciones positivas de las prácticas de Freinet para la enseñanza y la actualidad de estos métodos para la construcción de una práctica docente significativa y democrática.

Palabras clave: Pedagogía de Freinet. Práctica docente. Métodos alternativos. Innovación pedagógica.

\section{Introdução}

O presente trabalho justifica-se, primeiramente, pela relevância de Célestin Freinet enquanto educador contemporâneo e revolucionário que contribuiu significativamente com o campo educacional através de sua vida e sua obra. Além disso, é um trabalho que emerge de nossas inquietações em relação aos métodos criados por Freinet e as possibilidades que estes oferecem para a construção de uma prática docente significativa e democrática.

Segundo Tornaghi (1995), Freinet se diferenciou da maioria dos outros importantes pensadores e teóricos da educação por ter sido ele mesmo um professor primário e ter atuado em sala de aula por quase toda a sua vida. Toda a sua trajetória e experiência pedagógica deriva diretamente do trabalho desenvolvido com os alunos na busca de propostas que os levassem a gostar da escola e do trabalho, que os levassem a ser cidadãos conscientes e participantes críticos do meio social.

Embora não fosse um acadêmico, conforme afirma Sampaio (2007), Freinet não ignorava os debates pedagógicos de seu tempo, de sorte que, em 1924, foi à Suíça participar do Congresso da Liga Internacional para a Educação Nova, onde encontrou com os grandes educadores da época para conhecer os princípios da Escola Nova, corrente de pensamento para a qual 
a aprendizagem acontece pela atitude ativa da criança e não por imposição do professor.

De forma geral, a escola do século XIX, conforme aponta Imbernón (2012), era muito rígida, uniformizadora, socialmente medíocre, autoritária, obsoleta e anacrônica. Porém, existia uma aceitação passiva deste tipo de escola por parte da sociedade. Somente no século XX, essa escola velha, ou tradicional, a qual Freinet preferia denominar como "escolástica", passa a ser questionada continuamente pela sociedade e pelos professores. É a partir dessas críticas à escola tradicional que surgem diversos educadores que propõem diferentes alternativas escolares, lutando para modificar a concepção de escola e os métodos de ensino. Eles ficaram internacionalmente conhecidos como os idealizadores da Escola Nova.

A Escola Nova, segundo Dussel e Caruso (2003) foi um movimento composto por pedagogos que criaram diversas propostas de transformação do ensino e do espaço da sala de aula. Tais propostas eram profundamente diferentes entre si do ponto de vista político, histórico, didático e pedagógico, mas se reuniram em organizações internacionais pela reforma da educação vigente, atualmente denominada como "tradicional". A maioria das escolas novas integraram-se ao movimento mundial, organizando congressos periódicos para debater e intercambiar experiências e para estabelecer os princípios educativos e organizacionais para o seu funcionamento. Assim, de acordo com Dussel e Caruso:

A escola nova foi objeto de um grande número de investigações. Foi denominada de diversas maneiras, uma vez que foi um movimento internacional - como a lógica do crescimento capitalista à qual, acreditamos, correspondia -, e foi também fortemente criticada. A escola nova como movimento abrangeu inúmeras correntes, expressões e propostas. Nomes tão diferentes como os de John Dewey, Maria Montessori, Ovídio Decroly, Jean Piaget (se o considerarmos pedagogo) e muitos outros faziam parte desse movimento (DUSSEL; CARUSO, 2003, p. 197)

Porém, segundo Rosa Sampaio (2007), Freinet sentiu-se sozinho ao perceber que a Escola Nova era aplicável a escolas que tivessem instalações adequadas e com suporte para realizar as atividades propostas, e isso estava muito distante da realidade da escola em Bar-sur-Loup, que não possuía boas condições. Assim, Freinet realizou uma experiência singular em relação à 
Escola Nova, pois buscava um caminho que alcançasse a todos, que pudesse satisfazer a todas as crianças, valorizando suas diferenças, sem distinções, compreendendo sua inteligência, caráter e condição social, uma proposta inclusiva em sua essência. Pretendia encontrar técnicas que fossem acessíveis para todas as crianças, que as mobilizassem motivando o aprendizado e respeitando o rendimento escolar de cada um. Buscava uma forma de ensinar que procurasse respostas a questões colocadas pelos centros de interesse da criança, que não estão baseados na escola, mas na sua vida e cultura. Nessa direção, Marc Audet assevera:

A Pedagogia Freinet se apoia sobre valores pedagógicos e sociais específicos; funda também a sua ação sobre uma concepção precisa do homem e da aprendizagem. É também uma pedagogia materialista. Não se propõem apenas valores e um ideal; mas a cada princípio, a cada afirmação, corresponde uma prática, uma ferramenta ou uma técnica que permitam concretizar essa crença (AUDET, 2010, p. 257).

Nesse contexto de educar pela ação, Freinet desenvolveu diversas práticas de ensino com o objetivo de trazer a vida para dentro da sala de aula e tornar o ensino mais interessante e conectado com a realidade dos alunos. Na Pedagogia Freinet, através da sua proposta curricular e didática de trabalho, a relação teoria-prática se torna muito estreita, pois a criança aprende a teoria através da prática, partindo de uma necessidade sua. Aprende a escrever porque precisa se comunicar, bem como aprende a compartilhar e a colaborar a partir do desejo de construir e fazer parte do grupo. Isso é que resulta em uma aprendizagem significativa, a junção entre a necessidade da criança e uma finalidade concreta em cada prática.

Dessa forma, o presente trabalho pretende discutir algumas das práticas desenvolvidas por Freinet e sua atualidade com o intuito de compreender o seu desenvolvimento em seu caráter pedagógico inovador. Para tanto, abordamos três práticas extremamente relevantes para o entendimento da Pedagogia Freinet e seus fundamentos, quais sejam: o texto livre, o trabalho colaborativo e o jornal escolar.

A atualidade de Freinet e de sua Pedagogia é inquestionável, isso pode ser percebido a partir de seu pensamento visionário de trazer elementos da vida e do meio social da criança para dentro da sala de aula, gerando interesse e curiosidade nas crianças. Suas técnicas que estimulam o envolvimento 
dos alunos com a escrita e a leitura de forma concreta foram impactantes para a sua época e continuam sendo. Seu ideal de sociedade, buscando a cooperação e a democracia, onde todos tem voz e todos se responsabilizam por um projeto em comum é revolucionário, dá às crianças senso de responsabilidade por si e pelo coletivo.

A Pedagogia Freinet estabelece uma nova relação entre o professor e o aluno, e entre os alunos e seus pares, promovendo uma utilização diferente do material pedagógico e novos ambientes de aprendizagem, mostrando que nem toda aula precisa ser em sala de aula, e que é possível aprender no meio ambiente, na natureza e em outros espaços. Audet (2010, p. 267) afirma que "[...] os grandes eixos da Pedagogia Freinet, definidos inicialmente, são sempre os mesmos. As crianças de hoje têm sempre as necessidades daquelas de outrora: expressar-se, comunicar-se, aprender, organizar-se".

E é em torno dessas necessidades da criança - de expressão, comunicação e aprendizagem - que a Pedagogia Freinet se afirma e se perpetua com o passar dos anos como uma prática pedagógica coerente e eficaz, pois estudar e aplicar o pensamento de Freinet significa estar em constante descobrimento enquanto docente, mantendo esperança na vida e no poder transformador da educação.

Por fim, o presente artigo está estruturado em três seções. A primeira discorrerá sobre o texto livre e suas implicações enquanto método de ensino da leitura e da escrita, analisando quais as possibilidades e aprendizados que podem ser alcançados através do uso do texto livre. A segunda tratará da organização e da aplicação do trabalho colaborativo nas classes Freinet, questionando a importância dessa forma de trabalhar em sala de aula. E a terceira trará o jornal escolar enquanto prática pedagógica inovadora discorrendo sobre a produção do jornal e a sua divulgação.

\section{Texto livre e sua importância para a aprendizagem}

Esta seção aborda a técnica desenvolvida por Freinet, denominada como texto livre, buscando, em um primeiro momento, conceituar e contextualizar esta prática no período histórico em que foi idealizada, discorrendo sobre as mudanças incorporadas no ensino através do uso desse método. Em seguida, pretende apontar os motivos pelos quais a técnica tornou-se importante 
para o aprendizado da criança e, por último, discorre sobre os efeitos e resultados desse método na aprendizagem infantil.

De acordo com Freinet (1974), a intenção era substituir a rotina dos manuais, dos trabalhos de casa e das lições sem significado real para a criança, que eram geralmente impostos autoritariamente pelos adultos, pelo texto livre, que é a expressão natural inicial da vida infantil e uma prática na qual impera o verdadeiro sentido da escrita. Nesse sentido, também é possível fazer uso de outras formas de expressão, como o desenho, a pintura e a música livres, complementos através da via afetiva e artística, tudo o que a criança tem em si como possibilidades de acesso à cultura, não apenas escolar, mas a cultura social e humana.

A prática da livre expressão parte do princípio de dar palavra ao aluno, fornecendo-the meios de expressar-se e comunicar-se. Segundo Santos (1993), a expressão livre não é apenas um ponto de partida ou um simples meio, mas uma finalidade de aprendizagem, uma prática que possibilita ao aluno desenvolver suas potencialidades, ampliando cada vez mais as suas capacidades de criação, de comunicação e de expressão. Isso faz com que a criança avance o máximo possível na construção do saber.

Freinet foi um dos pioneiros da Escola Nova, destacando-se por seus métodos pedagógicos inovadores que respeitavam o desenvolvimento da criança. Sua intenção era entender os interesses das crianças e saber o que as motivava a aprender. Como grande crítico da escola tradicional, Freinet considerava a redação escolar, imposta e pré-determinada pelos professores, um trabalho alienado, fruto de um método artificial e engessado que não possibilitava que fosse captada toda a sensibilidade e criatividade infantil, apesar de lógico e científico.

Sampaio (2007, p. 24) destaca que "[...] nessa época, a escola tradicional não exigia que a criança, nos primeiros anos de escolaridade, expressasse um pensamento ou ideia própria através da escrita [...]" porque não acreditava na potencialidade das crianças de produzir e sistematizar textos. Somente a partir do trabalho desenvolvido por Freinet, as crianças começam a ter liberdade para expressar suas ideias, sentimentos e interesses no ambiente escolar.

Partindo desse pressuposto, o texto livre se mostra como um dos mais importantes instrumentos pedagógicos desenvolvidos por Freinet. É um texto no 
qual a criança pode se expressar livremente, escolhendo a temática sobre a qual deseja escrever. Segundo as técnicas do pedagogo francês, o texto livre é o eixo do trabalho da escola e o fio condutor de todas as práticas pedagógicas. É considerado por ele um método natural de tentativa experimental para aprendizagem da leitura e da escrita, pois parte do interesse da criança em escrever sobre determinado tema e se constitui progressivamente conforme o texto é corrigido e aperfeiçoado. Foi uma inovação para o seu tempo e se perpetuou na escola contemporânea como uma prática significativa de ensino, através de Freinet e de outros autores.

De acordo com Freinet (1973, p. 40), "[...] o essencial é que a criança sinta o valor, o sentido, a necessidade, o alcance individual e social da escrita-expressão". Desse modo, o texto livre emergia da imaginação, da originalidade da mente infantil e das experiências dos estudantes, daquilo que queriam expressar, do que thes interessava e que, na sua concepção, interessaria também aos colegas, com os quais iriam corrigir o texto coletivamente. As produções eram escritas no quadro, lidas por todas as crianças em conjunto, eram sugeridas as correções, tanto pelo professor quanto pelas crianças, e, em seguida, caso fossem autorizadas, eram feitas as correções. Somente depois desse processo de correção, os textos eram copiados pela turma, para que todos tivessem acesso ao registro das produções.

Para Freinet, é o uso real da escrita e da leitura que as torna muito mais do que simples matérias escolares para as crianças, continuações de suas vidas, o ensino se torna contextualizado e não algo que precisa apenas ser memorizado e repetido. Nas classes Freinet, os estudantes têm a possibilidade de escrever e desenhar livremente, sobre o que desejam expressar e com o estilo que preferirem. Audet $(2010$, p. 261$)$ afirma que "[...] todo o trabalho técnico que permite a uma escrita ser mais eficiente, a gramática, a sintaxe, é integrado à medida das necessidades de cada escritor; só assim a escrita assume um sentido de necessidade para a criança".

De acordo com Santos (1993), o texto livre é uma ferramenta didática que reúne uma série de atividades, englobando diversas habilidades, como, por exemplo, a redação, a leitura oral e silenciosa, a análise do conteúdo de um texto, a análise linguística nos níveis ortográfico, morfológico, sintático e semântico, a identificação de normas gramaticais definidas pelo "bom uso da linha", a revisão crítica e reelaboração de textos e, por fim, a leitura, a análise, 
o estudo comparativo e o debate sobre a produção escrita de diferentes autores, renomados ou não.

Na concepção de Imbernón (2012, p. 34), o texto livre pode ser considerado "[...] um método natural que não tem exercícios metódicos, modelos impostos e correções gráficas. A criança, de sua própria maneira, mediante o tateamento experimental, adquire a leitura e a escrita por meio do estudo global [...]" a partir da leitura do seu próprio texto e dos textos dos colegas.

A atitude pedagógica de Freinet, em que o professor dá liberdade para a criança escolher é, em sua essência, revolucionária, tendo em vista o momento histórico em que suas práticas foram desenvolvidas. As crianças quase não eram ouvidas, tampouco questionadas sobre o que queriam ou não. Enquanto a escola tradicional pouco questionava e muito impunha, Freinet vislumbrou na liberdade a chave para despertar o interesse e uma real motivação nas crianças, pois a partir do momento que elas decidiam escrever algo, se responsabilizavam pela produção que seria realizada. Segundo Élise Freinet (1979, p. 12), o elemento central da obra de Freinet é a livre expressão, pois ele mesmo afirmava que "[...] a livre expressão não é invenção do cérebro particularmente privilegiado: é a própria manifestação da vida!".

$\bigcirc$ conceito de liberdade utilizado na Pedagogia Freinet se coloca na invariante $n^{\circ} 7$, contida em seu livro "As invariantes pedagógicas", na qual Freinet (1964, p. 66) ressalta o fato de que "[...] todos gostam de escolher seu próprio trabalho, mesmo que a escolha não seja a melhor". Desse modo, criar um ambiente propício para dar liberdade para as crianças escolherem, se torna um conceito-chave nas ideias de Freinet.

Conforme afirma Scarpato (2017), para Freinet, liberdade significa cada homem construir sua concepção de mundo com respeito mútuo, expressando seus pontos de vista, construindo assim os fatos cotidianos da vida pessoal e do grupo, com discernimento, livre de imposições e incompreensões.

A liberdade de expressão é fundamental em todo processo de escrita, se faz necessário que o professor estimule as crianças a escreverem com naturalidade, compreendendo a importância do ato de escrever e conhecendo sua real utilidade. Segundo Santos (1993), só assim é possível eliminar as censuras, ajudando a criança a perder o medo de escrever, sensibilizando-as para a escrita, propiciando que experimentem o prazer de conhecer as palavras, imagens, sonoridades e ritmos, estimulando a relação estabelecida entre as 
crianças e a escrita, para que não seja uma relação unicamente passiva, e provocando o interesse dos alunos, que de outro modo não se soltariam para escrever.

Por esse motivo, Freinet considerava a livre expressão e, em especial, o texto livre, como ferramentas fundamentais para o ensino, pois a criança se sentia confortável para experimentar e realizar suas tentativas e erros através da liberdade de escolher, ciente de que o professor sempre estava ali para responder às suas dúvidas e orientar quando fosse preciso.

\section{Trabalho colaborativo para um ensino democrático}

Esta segunda seção discorrerá sobre o trabalho colaborativo desenvolvido nas classes Freinet, visando, em um primeiro momento, conceituar e contextualizar esta forma de organização da sala de aula como estrutura cooperativa. Também investiga as práticas por meio das quais essa cooperação se concretiza. Em seguida, tratará da importância de construir coletivamente o conhecimento e suas implicações no desenvolvimento dos alunos. E, posteriormente, aborda o trabalho colaborativo como ferramenta essencial para a construção de um ensino democrático.

Freinet (2004) afirmava que um canteiro de obras, por exemplo, não se resume a um arquiteto com suas plantas na mão que explica, ensina e comanda. É a partir da colaboração dos operários e das máquinas que na realidade se constroemos projetos do coordenador. E é esse o canteiro de obras que o professor deve organizar, onde existe alguém que orienta, que instrui, mas em contraponto existem outros que realizam juntos, cada um à sua maneira.

Trabalhar de forma cooperativa em sala de aula é um poderoso instrumento pedagógico, pois possibilita um movimento de ajuda mútua entre os alunos, sem rejeitar suas individualidades, muito pelo contrário. Através da colaboração as crianças aprendem a respeitar a diversidade e as diferenças, se tornam pessoas capazes de escutar e reconhecer umas às outras, valorizando-se e favorecendo a participação e integração social.

Célestin Freinet não aceitava a competição individual que existia nas escolas, típica da época e tão presente ainda hoje entre os alunos, por esse motivo idealizou e propôs uma vivência cooperativa nas suas classes, 
buscando reconhecer o individual e o coletivo, para mobilizar todos no sentido da colaboração para o aperfeiçoamento em grupo. $\bigcirc$ conceito de cooperação em Freinet é essencial para que possamos entender suas práticas e seus ideais de sociedade. A cooperação é uma forma de interação social, na qual os sujeitos se empenham na obtenção de um fim coletivo e comum, sendo assim imprescindível na constituição de cidadãos que possam viver em sociedade e trabalhar coletivamente. Segundo Imbernón:

Freinet lança um debate que, décadas mais tarde, será importante: o debate sobre a homogeneização e os circuitos segregadores que determinadas escolas estabelecem. Nessa época, falava-se de trabalho individual, fracasso, dificuldades etc. Empregava-se uma linguagem diferente, mas o conceito e o processo que se queria desenvolver eram os mesmos; ou seja: o que podemos fazer nas salas de aula para não participar de uma seleção cultural e, ao contrário, para que todos os alunos de procedências diferentes, de culturas diversas, sejam atendidos de forma adequada e possam interiorizar em sua vida esse respeito às diferenças e não cair na exclusão social? Era uma preocupação de Freinet e também da atualidade (IMBERNÓN, 2012, p. 86).

É a partir dessa preocupação que Freinet desenvolveu um formato de vivência e de trabalho em suas classes que ficou popularmente conhecido como trabalho colaborativo, formato este que tem se mostrado cada vez mais importante para a dinâmica da escola, visando a necessidade de lutar contra as tendências individualistas da sociedade e da escola tradicional. Com o intuito de desenvolver a cooperação, Freinet implementou em suas classes técnicas que pudessem desenvolver o trabalho colaborativo entre as crianças: 0 mural de notícias, a assembleia cooperativa semanal e as conferências, como as principais.

O mural de notícias é um mural dividido em três seções identificadas em envelopes, quais sejam: crítico, felicito e sugiro. A partir das seções, as crianças podem se expressar colocando o que criticam: alguma atitude de um colega ou professor, algum fato que aconteceu na semana e foi desagradável ou o que entenderam que merece uma crítica. $\bigcirc$ que felicitam: alguma atitude que queiram enaltecer, alguma atividade que gostaram ou algo que, por algum motivo, mereça um elogio. Por fim, o que sugerem: o que pode melhorar ou pode ser feito de outra forma. A única regra para que as crianças coloquem 
textos no mural é que o recado precisa ser assinado pela criança que escreveu. Sobre essa questão, Elias conclui:

Freinet vai mais longe: sua pedagogia circula entre o individual e o coletivo, procurando desenvolver ao máximo o senso cooperativo. Existe um Conselho de Classe que reúne semanalmente professores e alunos, sob a coordenação de um dos membros (geralmente um aluno), para tomar decisões ligadas à vida da classe, organização de material, trabalho, atividades a serem realizadas, prazos, responsabilidades (ELIAS, 2010, p. 65).

conselho de classe citado por Elias é a assembleia cooperativa semanal. Segundo Santos (1993), funciona da seguinte: reserva-se uma aula no início ou no fim da semana para que seja realizada a reunião, as crianças se sentam em círculo para facilitar os diálogos, a pauta da reunião são os textos colocados no mural de notícias e a equipe responsável pela condução da assembleia é indicada e votada pela turma. A equipe precisa ser composta por um presidente, um vice-presidente, um secretário e um vice-secretário, que serão os responsáveis pela leitura dos bilhetes, por dar a palavra às crianças, pelo registro escrito da reunião e das decisões tomadas, e pela colagem dos bilhetes no caderno de reuniões.

Quando não é possível fazer a leitura de todos os bilhetes durante a reunião, que equivale ao tempo de uma aula, os bilhetes não lidos são rasgados. Porém, é possível que o autor do bilhete o reescreva e o coloque novamente no mural para ser discutido na próxima reunião. De acordo com Santos:

Esse procedimento é adotado no sentido de levar os alunos a perceberem: a limitação imposta pelo tempo, a importância da brevidade e da concisão para se garantir a existência de um maior número de intervenções, a necessidade de cada um adotar uma postura mais seletiva com relação ao conteúdo dos seus bilhetes, em função do interesse e da importância que os assuntos nele abordados possam ter para o grupo (SANTOS, 1993, 149).

Desse modo, a assembleia cooperativa semanal pode ser considerada como um instrumento pedagógico valioso, já que estimula as crianças a analisarem e refletir sobre suas atitudes, sua rotina escolar, sobre as práticas cotidianas e, assim, as torna responsáveis por administrar a sua vida escolar, 
entendendo o desenvolvimento de cada um e motivando a superação das dificuldades individuais e coletivas.

As conferências, assim como a reunião cooperativa, são desenvolvidas e preparadas pelas crianças a partir de um tema que tenham interesse em pesquisar e apresentar para a turma. A prática de realizar conferências, que podem ser entendidas como um tipo de palestra, possibilita, segundo Imbernón (2012), que a criança desenvolva formas de se expressar, fazendo uso de diferentes instrumentos, como esquemas, textos, desenhos, audiovisuais, motivando-as a ler e a escrever sobre o tema que escolheram. Ou seja, parte do interesse da criança falar e discutir em público com a turma, apresentando seus pontos de vista e os debatendo com o grupo.

A partir dessas técnicas, é possível compreender o que significa o trabalho colaborativo na Pedagogia Freinet, uma forma de organização da estrutura de convivência na sala de aula, na qual se faz uso de práticas de diálogo para concretizar a cooperação. Esses instrumentos pedagógicos buscam colocar a criança no centro do processo de aprendizagem, tornando-a responsável por seu desenvolvimento e não um indivíduo passivo.

O trabalho colaborativo, como já citado anteriormente, é um elemento 12 essencial na Pedagogia Freinet que leva à compreensão da concepção freinetiana de educação, trabalho e sociedade. Para tanto, é necessário, conforme Imbernón (2012), tornar a escola uma comunidade cooperativa, baseada no trabalho e na cooperação, que lute contra o autoritarismo do professor, motive a colaboração entre alunos e professores e repudie a competição como um instrumento pedagógico para motivar o aluno, pois esta só produz individualismo e prejudica a formação integral da criança.

Freinet (1974) afirmava, em sua invariante pedagógica número 27 , que a democracia de amanhã se prepara por meio da democracia na escola, pois um regime autoritário na escola é incapaz de formar cidadãos democratas. Desse modo, vislumbrava no trabalho colaborativo uma forma concreta de inserir as crianças em uma vivência democrática dentro das salas de aula e das escolas e em um processo democrático de ensino. Nele, a criança tem a possibilidade de se autogovernar, refletir, se organizar e agir, tendo em vista que um ensino autoritário e imposto incapacita as crianças de desenvolverem as habilidades intelectuais e sociais. 
Em toda a obra de Freinet, os aspectos políticos e sociais caminharam lado a lado com os educacionais, pois, segundo Elias (2010), o autor entendia que os interesses das classes sociais invadiam todos os espaços da vida social e da escola, e esse fato não poderia ser ignorado. $O$ que Freinet pretendia era destacar o quanto uma prática comprometida em sala de aula, pode contribuir para a constituição de educandos esclarecidos, futuros trabalhadores e cidadãos democratas, que tenham condições de defender seus interesses e construir uma sociedade melhor. Assim, Freinet esclarece:

Na Escola, devem-se conservar ordem, disciplina, autoridade e dignidade, mas a ordem que resulta de uma melhor organização do trabalho, a disciplina que se torna solução natural de uma cooperação ativa no seio da nossa sociedade escolar, a autoridade moral primeiro, técnica e humana depois, que não se consegue com ameaças ou castigos, mas por um domínio que leva ao respeito; a dignidade da nossa função comum de professores e de alunos, a dignidade do educador que não se pode conceber sem o respeito total pela dignidade das crianças que ele quer preparar para a função de homens (FREINET, 2004, p. 72).

Freinet acreditava que o principal objetivo da educação era possibilitar o crescimento pessoal e social da criança através da cooperação e do respeito para que cada criança estivesse preparada, não apenas para a sociedade atual, mas para uma sociedade melhor, mais humana e democrática. Portanto, é possível concluir que a cooperação é um poderoso instrumento, não só para construir um ensino democrático dentro da escola, como também para a construção de uma sociedade democrática e igualitária.

\section{Produção do jornal escolar e suas implicações no ensino}

Nesta terceira e última seção, o foco será o jornal escolar, prática desenvolvida por Freinet com o intuito de envolver as crianças, despertando seu interesse genuíno e transformando-as em autoras do seu processo de aprendizagem. Desse modo, trataremos da produção do jornal escolar enquanto prática pedagógica e quais são as suas implicações no ensino das crianças. Em seguida, discorreremos sobre a divulgação do jornal e seus impactos no processo de aprendizagem. De acordo com Freinet: 
Quando os cidadãos souberem que o jornal pode mentir ou, pelo menos, que ele pode apresentar como definitivas soluções que não passam de aspectos parciais dos problemas impostos pela vida; quando estiverem aptos a discutir com prudência, mas também com ousadia, quando tiverem uma formação baseada na investigação experimental e na criatividade [...], haverá então qualquer coisa de diferente nas nossas democracias (FREINET, 1974, p. 45).

A prática do jornal escolar, não busca produzir uma imitação ou um substituto para os jornais convencionais que são comercializados, mas tem como objetivo ser uma expressão fiel dos interesses das classes que serão representados pelo conjunto de textos e desenhos criados para constituir os jornais. Através da produção do jornal, é possível reconhecer, respeitar e valorizar a expressão e o trabalho de cada uma das classes e das crianças que as compõem, bem como possibilitar que cada aluno vivencie a experiência de ter seus pensamentos, imaginações, opiniões e aventuras materializadas em um texto impresso.

A proposta de ensino de Freinet tem suas bases na livre expressão, na observação e na experiência, porém, conforme o próprio Freinet (1974, p. 14 8) afirma, essas técnicas pedagógicas pressupõem "[...] a criação de novos utensílios de trabalho que the dão simultaneamente o alimento e o objetivo". Dessa forma, surgiu o jornal escolar, a partir do desejo de Freinet (1974) de desenvolver um novo método de trabalho que desse significado à sua forma de trabalhar com as crianças e fosse mais coerente com os seus objetivos de ensino. Além disso, o pedagogo francês buscava práticas pedagógicas que melhor se encaixassem nos hábitos já desenvolvidos nas escolas, nas necessidades de aprendizagem das crianças de seu tempo, bem como nas exigências de escrita e produção da época.

Para alcançar esse objetivo, Freinet buscou os tipógrafos que trabaIhavam na cidade de Grasse para que the orientassem sobre como deveria fazer para comprar uma impressora. E, assim, introduziu a prensa escolar em suas classes, dando aos alunos a chance de imprimir e compartilhar os textos livres que eram produzidos por eles e que, na maioria dos casos, ficavam registrados apenas em seus cadernos sem que mais ninguém pudesse os ler. De acordo com Audet: 
A imprensa como instrumento pedagógico de comunicação foi certamente o ponto forte da inovação de Freinet em matéria linguística, e não foi por acaso que ele, militante da causa proletária, teve essa ideia. A imprensa e as tipografias foram, no início da luta operária, o trabalho nobre por excelência. Imprimir é trabalho manual que concretiza e difunde o pensamento. Mas é também nesse momento que se concentra e, de certo modo, se venera a correção do idioma. Não se trata de trabalho a ser feito de qualquer maneira (AUDET, 2010, p. 20).

entendimento e a seriedade de perceber que os textos não poderiam ser feitos de qualquer maneira trouxeram grandes vantagens para 0 processo de aprendizagem, alcançadas a partir da possibilidade de imprimir e expor os materiais produzidos. Segundo Sampaio (2007), houve, por parte das crianças, um aumento de interesse por escrever, que surpreendeu até o próprio Freinet, elas desejavam ver logo seus textos impressos e mostrá-los para seus familiares e amigos. A partir desse novo recurso, as crianças davam sentido para o processo de escrita e leitura, viam concretamente o texto em sua função social, pois escreviam com uma finalidade bastante clara: comunicar algo a alguém.

Após a produção dos textos, a escolha, democraticamente votada, de quais seriam impressos e dos aperfeiçoamentos feitos pela turma e pelo professor, o processo de impressão do jornal se desenvolve a partir de etapas tão minuciosas quanto as primeiras. Freinet (1974) explica que a composição tipográfica é demorada e um pouco cansativa. $\bigcirc$ primeiro passo é separar os caracteres, em seguida, é preciso compor as palavras, letra por letra, e depois o texto, linha por linha. Ainda assim, Freinet (1974) afirma que, na prática, imprimir é um trabalho que nunca se torna tedioso e até os adultos se deixam seduzir por uma técnica tão detalhista que possibilita a transcrição, numa forma esteticamente melhorada, de textos a que se quer dar vida. Conforme destaca Freinet:

A criança que compõe um texto sente-o nascer enquanto trabalha; dá-the uma nova vida, torna-o seu. Deixa de haver um intermediário no processo que vai do pensamento balbuciado e depois expresso, ao jornal que será mandado pelo correio para os correspondentes. Controla todas as etapas: escrita, aperfeiçoamento colectivo, composição tipográfica, ilustração, disposição sob a prensa, tintagem, tiragem, agrupamento, agrafagem. É precisamente esta 
continuidade artesanal que constitui o essencial do alcance pedagógico da Imprensa na Escola (FREINET, 1974, p. 20).

A partir da impressão e, consequentemente, da produção do jornal, o aluno traz vida ao seu texto e dessa forma aprende com a prática que os textos precisam estar legíveis e bem apresentados para se tornarem atraentes e agradáveis aos leitores. Com base nisso, segundo Santos (1993), as crianças têm seu interesse despertado, o que facilita a aprendizagem da escrita e dos conceitos básicos de ortografia, do uso de diferentes elementos para compor frases e do emprego dos sinais gráficos.

Contudo, é necessário destacar, que não é apenas o uso da técnica do jornal escolar que a torna significativa, mas sim a metodologia adotada no trabalho de elaboração e divulgação do jornal escolar que the garante o caráter de instrumento pedagógico transformador. Segundo Santos:

Mais importante do que o jornal, como produto final, é o esforço conjunto para fazê-lo; é a iniciativa assumida; é a decisão tomada em diversas circunstâncias; é o confronto de ideias havido; é, enfim, a enorme gama de interações estabelecidas nos mais diferentes níveis, no decorrer do processo de sua realização (SANTOS, 1993, p. 67).

Diante disso, torna-se possível compreender o jornal escolar como um método complexo, no qual todos precisam colaborar por um objetivo em comum: desenvolver o jornal da melhor maneira possível, o que significa aprender e se empenhar da melhor forma. De acordo com Freinet (1974, p. 48): "[... ] cada página do jornal é como um degrau na lenta escalada da educação e da cultura: ela materializa e idealiza o esforço. É a medida da Escola".

No entanto, é preciso compreender que as habilidades resultantes desta prática não se limitam restritamente à escrita, mas, sim, envolvem as diversas áreas do conhecimento de forma transversal com base nos temas abordados pelos correspondentes, bem como possibilita a ampliação de habilidades sociais ao longo do processo de correspondência, que é fundamental para o pleno desenvolvimento do aluno. 


\section{Considerações finais}

Através do trabalho que desenvolveu e continua desenvolvendo por meio dos adeptos de sua pedagogia, Célestin Freinet tem se consolidado ao longo dos anos como um dos grandes educadores contemporâneos. Seu legado e suas contribuições para o campo educacional continuam a ecoar e a trazer esperança e otimismo para todos que, assim como ele, acreditam fortemente em uma educação democrática que enxergue a criança em sua totalidade e que busque sempre novos caminhos para ensinar. Freinet foi um grande entusiasta da educação e, além de um teórico, foi um professor prático, que desenvolveu todas as suas técnicas em classes primárias, sempre em contato direto com as crianças a quem ensinava. Segundo Sampaio (2007, p. 7): "Freinet anotava tudo, estudava, discutia e, pouco a pouco, ia descobrindo seu próprio caminho, aquele que, no fundo, Ihe parecia o mais simples, o mais lógico, o de maior bom-senso".

Para o desenvolvimento deste artigo, analisou-se na Pedagogia Freinet o texto livre, o trabalho colaborativo e o jornal escolar, procurando compreender como essas práticas pedagógicas foram elaboradas e como eram aplicadas no processo de ensino-aprendizagem, bem como sua atualidade e as possibilidades de aplicação nas escolas atuais. Para alcançar esse propósito foi realizada pesquisa bibliográfica em obras do próprio Freinet e de autores que o estudam, tendo em vista o melhor desenvolvimento e aprofundamento deste trabalho. Desta forma, o texto livre, o trabalho colaborativo e o jornal escolar, além de se constituir no cerne da Pedagogia Freinet, são práticas pedagógicas conectadas e articuladas no cotidiano escolar de clave freinetiana. Parte-se do texto livre, que leva ao trabalho colaborativo e à confecção do jornal escolar.

presente trabalho instigou a realização de outras investigações de caráter pedagógico. Em primeiro lugar, a pesquisa sobre apropriações específicas da Pedagogia Freinet como, por exemplo, a elaboração do jornal escolar pelos estudantes. Trata-se de constatar como a imprensa escolar se disseminou a partir da ação pioneira de Célestin Freinet. De outra parte, pode-se pensar como o trabalho colaborativo foi utilizado em outras propostas educativas como a pedagogia personalizada e comunitária, desenvolvida por Pierre Faure e pelo método Paulo Freire. Ademais, é instigante pensar como as três práticas pedagógicas freinetianas foram hibridizadas nas escolas alternativas e democráticas que emergiram a partir da década de 1960. 


\section{Referências}

AUDET, Marc. A pedagogia Freinet. In: GAUTHIER, Clermont; TARDIFF, Maurice A pedagogia: teorias e práticas da Antiguidade aos nossos dias. Tradução Lucy Magalhães. Petrópolis: Editora Vozes, 2010.

DUSSEL, Inés; CARUSO, Marcelo. A invenção da sala de aula: uma genealogia das formas de ensinar. São Paulo: Moderna, 2003.

ELIAS, Marisa Del Cioppo. Célestin Freinet: uma pedagogia de atividade e cooperação/ Marisa Del Cioppo Elias. 9. ed. Petrópolis: Vozes, 2010.

FREINET, Célestin. Para uma escola do povo. Lisboa, Presença, 1973.

FREINET, Célestin. $\mathbf{O}$ jornal escolar. Tradução Filomena Quadros Branco. Lisboa, Editorial Estampa, 1974.

FREINET, Célestin. Pedagogia do bom senso. Tradução J. Baptista. 7. ed. São Paulo: Martins Fontes, 2004.

FREINET, Élise. O Itinerário de Celéstin Freinet: a livre expressão na Pedagogia Freinet. Tradução Priscila de Siqueira. Rio de Janeiro: Livraria Francisco Alves, 1979.

18 IMBERNÓN, Francisco. Pedagogia Freinet: a atualidade das invariantes pedagógicas. Tradução Alexandre Salvaterra. Porto Alegre: Penso, 2012.

SAMPAIO, Rosa Maria Whitaker. Freinet: evolução histórica e atualidades. 2. ed. São Paulo: Scipione, 2007.

SANTOS, Maria Lúcia dos. A expressão livre no ensino da língua portuguesa: pedagogia Freinet. São Paulo: Scipione, 1993.

SCARPATO, Marta. A livre expressão na pedagogia Freinet. Revista IberoAmericana de Estudos em Educação, Araraquara, v. 12, n. 1, p. 620-628, 2017.

TORNAGHI, Alberto. Educação pelo trabalho de Célestin Freinet. 1995. Disponível em: http://www.educacaopublica.ri.gov.br/biblioteca/educacao/0028c.html>. Acesso em: 23 jan. 2019. 
Prof. Dr. Norberto Dallabrida Universidade do Estado de Santa Catarina - UDESC (Brasil) Programa de Pós-Graduação em Educação Grupo de pesquisa História, tempo presente e culturas escolares Orcid id: htrps: / / orcid.org/0000-0002-5 100-2028 E-mail: norbertodallabrida@gmail.com

Denise Furtado Universidade do Estado de Santa Catarina - UDESC (Brasil) Licenciada em Pedagogia Grupo de pesquisa História, tempo presente e culturas escolares Orcid id: https: / / orcid.org/0000-0002-8588-2887 E-mail: deniise_furtado@gmail.com

Recebido 19 abr. 2021 Aceito 24 maio 2021 